\title{
Aspekty wprowadzania średniego poziomu zawartości etanolu do benzyny silnikowej. Część 1
}

\begin{abstract}
W artykule dokonano krótkiego przeglądu literatury poświęconej aktualnej sytuacji legislacyjnej dotyczącej paliwa E10+. Przytoczono przykłady wprowadzania paliw E10+ na rynki Ameryki Północnej i Południowej, a także przedstawiono plany Unii Europejskiej w tym zakresie. Zaprezentowano publikacje wyników badań związanych z wpływem zwiększenia zawartości etanolu powyżej 15\% (V/V) na właściwości charakteryzujące lotność, tj. prężność par i przebieg krzywej destylacji normalnej.
\end{abstract}

Słowa kluczowe: benzyna silnikowa E10+, etanol, prężność par, destylacja.

\section{Aspects of blending a mud level content of ethanol to motor gasoline. Part 1}

The article presents a brief review of the literature dedicated to the current legislative situation on E10+. The examples of the introduction of E10+ fuel into North and South American markets, as well as plans for the European Union. Publication of research results related to the impact of increased ethanol content above $15 \%(V / V)$ on the characteristics of volatility i.e. distillation curve and vapor pressure are presented.

Key words: petrol E10+, ethanol, vapor pressure, distillation.

\section{Wstęp}

Od stycznia 2015 r. w Polsce obowiązuje Ustawa z dnia 15 stycznia 2015 r. o zmianie ustawy o biokomponentach i biopaliwach ciekłych oraz niektórych innych ustaw [34]. Dokument ten dokonuje częściowego wdrożenia Dyrektywy Parlamentu Europejskiego i Rady 2009/28/WE z dnia 23 kwietnia 2009 r. W sprawie promowania stosowania energii ze źródeł odnawial- nych [31]. Zgodnie z wytycznymi dyrektywy, promowane jest zwiększanie udziału biokomponentów w paliwach, jako jednej z dróg ograniczania emisji gazów cieplarnianych. Odnosi się to także do bioetanolu w formule benzyny silnikowej.

Sytuacja dotycząca benzyny silnikowej E10+ nie jest jednak do końca klarowna. Z jednej strony z zapisów dyrektywy

\begin{tabular}{|c|c|}
\hline Kod celny & Opis wyrobu \\
\hline 2710 & $\begin{array}{l}\text { - Oleje ropy naftowej i oleje otrzymywane z minerałów bitumicznych, inne niż surowe; preparaty gdzie indziej nie } \\
\text { wymienione ani nie włączone, zawierające } 70 \% \text { masy lub więcej olejów ropy naftowej lub olejów otrzymywanych } \\
\text { z minerałów bitumicznych, których te oleje stanowią składniki zasadnicze preparatów; oleje odpadowe. } \\
\text { - Oleje ropy naftowej i oleje otrzymywane z minerałów bitumicznych (inne niż surowe) oraz preparaty gdzie indziej } \\
\text { nie wymienione ani nie włączone, zawierające } 70 \% \text { masy lub więcej olejów ropy naftowej lub olejów otrzymywa- } \\
\text { nych z minerałów bitumicznych, których te oleje stanowią składniki zasadnicze preparatów, inne niż te zawierają- } \\
\text { ce biodiesel i inne niż oleje odpadowe. }\end{array}$ \\
\hline 271012 & Oleje lekkie i preparaty. \\
\hline 27101245 & $\begin{array}{l}\text { - O liczbie oktanowej (RON) } 95 \text { lub większej, ale mniejszej niż } 98 . \\
\text { - Mieszanki benzyny z zawartością alkoholu etylowego ponad } \mathbf{1 0 \%}(\boldsymbol{V} / \boldsymbol{V}) \text {. }\end{array}$ \\
\hline 27101249 & $\begin{array}{l}\text { O liczbie oktanowej (RON) } 98 \text { lub większej. } \\
\text { - Mieszanki benzyny z zawartością alkoholu etylowego ponad } \mathbf{1 0 \%}(\boldsymbol{V} / \mathbf{V}) \text {. }\end{array}$ \\
\hline
\end{tabular}


98/70/WE, zmienionej dyrektywą 2009/30/EC [32], wynika, że definicja benzyny pozostaje w brzmieniu „benzyna oznacza mineralne oleje lotne przeznaczone do działania przymusowych silników z zapłonem iskrowym wewnętrznego spalania, używane do napędzania pojazdów i objęte kodami CN 271000 27, 271000 29, 271000 32, 27100034 oraz 27100036 " i zawiera nieaktualne kody celne. Zmieniona w 2014 roku Wspólna Taryfa Celna określiła nowe kody celne w grupie 2710 , obejmującej benzynę silnikową, o zapisach podanych przez Służbę Celną Rzeczypospolitej Polskiej System ISZTAR - Informacja Taryfowa [33].
Z zapisów zawartych w informacji taryfowej wynika, że tym samym kodem celnym określone są benzyny silnikowe o liczbie oktanowej 95 i 98 (lub większej) i mieszanki benzyny z zawartością alkoholu etylowego ponad $10 \%(V / V)$.

Tymczasem załącznik 1 dyrektywy FQD dopuszcza maksymalną zawartość etanolu w benzynie na poziomie 10\% (V/V), zgodnie z zapisem: „2. Państwa członkowskie zapewniają, że benzyna może być wprowadzona do obrotu na ich terytorium tylko wtedy, jeżeli będzie ona zgodna ze specyfikacjami środowiskowymi, określonymi w załączniku I". Ta kwestia niespójności przepisów prawnych wymagać będzie więc rozwiązania w przyszłości.

\section{Badania paliw etanolowych}

Pomimo nierozstrzygnięcia kwestii niespójności przepisów prawnych, w Europie prowadzone są badania zmierzające do opracowania specyfikacji jakościowej benzyny silnikowej, zawierającej powyżej 10\% (V/V) etanolu.

Już w projekcie badawczym BEST [2], realizowanym w latach 2005-2009, poświęcono uwagę paliwu HE15, które jest mieszaniną $85 \%$ benzyny bezołowiowej i $15 \%$ nieodwodnionego bioetanolu. Całkowita zawartość wody w tym paliwie wynosi $0,6 \%$. Może ono być stosowane w większości standardowych samochodów benzynowych bez modyfikacji silnika lub układu paliwowego, na co wskazywały testy paliwa przeprowadzone w Niemczech i Holandii. Dla dokonania oceny wpływu paliwa na silnik samochodowy przeprowadzono testy na niezmodyfikowanym samochodzie w hamowni podwoziowej. Wykazały one różnice $\mathrm{w}$ wynikach, co potwierdziło konieczność dalszych badań. Na podstawie ankiety, przeprowadzonej przez producenta paliwa wśród użytkowników HE15 na stacji paliwowej w pobliżu Rotterdamu, uzyskano następujące dane:

- większość użytkowników HE15 nie zaobserwowała różnicy pomiędzy stosowaniem HE15 i benzyny,

- dwie trzecie użytkowników stwierdziło, że zużycie paliwa było takie same jak w przypadku benzyny,

- około $20 \%$ użytkowników powróciło do stosowania tradycyjnej benzyny, bez podania przyczyny.

Według zapisów i definicji dyrektywy paliwowej FQD, paliwo to nie jest benzyną i nie może być obecne w tym charakterze na rynku, ale może być sprzedawane jako paliwo HE15 [2]. Dystrybucja HE15 wymaga oddzielnej infrastruktury, która została dostosowana w około 35 stacjach w Holandii, w ramach pomocy finansowej państwa [2].

W USA w latach 2010-2011 Amerykańska Agencja Ochrony Środowiska (EPA) zaaprobowała (EPA-HQOAR-2009-0211; FRL-9258-6) [6, 7] stosowanie paliwa E15 w samochodach produkowanych po 2001 roku, opierając się na licznych badaniach paliw E0-E20, w tym badaniach: emisji, efektywności pracy katalizatorów oczyszczania spalin, zużycia paliwa w odniesieniu do wartości opałowej, kompatybilności materiałów, właściwości eksploatacyjnych. Badania te przeprowadzono na 86 pojazdach, wykonując około 1000 testów emisji [21, 27, 28, 29].

W programie Horyzont 2020 [11] zawarty jest temat B.2.5: „Testy silnikowe dla nowych rodzajów biopaliw oraz rozwój norm dla biopaliw w ramach umowy o partnerstwie z CEN-CENELEC". Jedno z tych paliw to E20/E25. Celem jego badań jest określenie wpływu średniej zawartości etanolu na liczby oktanowe i zmiany jego lotności, a w konsekwencji - ustalenie limitów parametrów w specyfikacji. Dodatkowo oceniane będzie optymalne wykorzystanie energii $\mathrm{w}$ produkcji tego paliwa $\mathrm{w}$ stosunku do uzyskiwanej liczby oktanowej benzyny. W latach 70. XX wieku, w programie RUFIT [25] zostały przeprowadzone badania w celu ustalenia optymalnej liczby oktanowej benzyny bezołowiowej na rynku europejskim. Badania te wykazały wzajemny wpływ pomiędzy zmniejszeniem zużycia paliwa w silniku, poprzez zaprojektowanie silników do spalania paliwa o wyższej liczbie oktanowej, a wzrostem zużycia energii w produkcji benzyny o wyższej liczbie oktanowej. Obecnie, wzorem tamtego programu, podjęto działania w celu uruchomienia programu RUFIT2, w którym oceniane będą wzajemne relacje liczb oktanowych benzyny E10+ i efektywności produkcji benzyny w rafinerii $\mathrm{w}$ aspekcie optymalnego całościowego wykorzystania energii. Ponadto zostanie dokonany przegląd parametrów lotnościowych benzyny oraz ocena ewentualnych zmian w konstrukcji silnika, poziomów liczb oktanowych RON/MON i ocena redukcji emisji gazów cieplarnianych $\mathrm{w}$ analizie cyklu życia paliwa. 


\section{Wpływ etanolu na lotność benzyny silnikowej}

Oprócz liczb oktanowych krytyczną właściwością paliw do silników o zapłonie iskrowym jest lotność. Łączy ona ze sobą dwa parametry, które są istotne dla właściwej pracy silnika samochodowego o zapłonie iskrowym, tj. skład frakcyjny i prężność par. Utworzenie w silniku właściwej mieszanki paliwowo-powietrznej wiąże się, między innymi, ze zdolnością paliwa do szybkiego odparowania w różnych warunkach temperaturowych danego regionu klimatycznego. Zdolność ta $\mathrm{z}$ kolei jest związana z ilościami odpowiednich frakcji węglowodorowych obecnych w benzynie silnikowej, a także z ilością, między innymi, etanolu. Znany wpływ etanolu w zakresie niskich jego udziałów w benzynie silnikowej, do $10 \%(V / V)$, wyraża się nieaddytywnym podwyższeniem szczególnie ilości cieczy odparowującej do $70^{\circ} \mathrm{C}$ i drastycznym podwyższeniem prężności par. Stwarza to określone problemy eksploatacyjne, dla uniknięcia których należało odpowiednio zaprojektować skład węglowodorowy benzyny bazowej, do której dodawany jest etanol. W przypadku benzyny silnikowej zawierającej powyżej $10 \%(V / V)$ etanolu o tzw. średnim poziomie zawartości (np. E15, E20), wpływ etanolu na lotność i inne związane z nią parametry pracy silnika samochodowego, jak emisja spalin czy emisja parowania, jest obecnie w Europie na etapie badań.

\section{Wpływ etanolu na przebieg krzywej destylacji}

Etanol lub metanol z benzyną silnikową tworzą mieszaniny azeotropowe z efektem pozytywnym $[5,15,17,23,24]$. Na wykresie krzywej destylacji przedstawiana jest zależność ilości frakcji paliwa odparowujących do danych temperatur. W przypadku mieszanin azeotropowych etanolu $\mathrm{z}$ benzyną silnikową wpływ azeotropu na kształt krzywej destylacji przejawia się jej spłaszczeniem w temperaturze wrzenia azeotropu [17]. Krzywa destylacji dostarcza informacji o zakresach wrzenia paliwa (tak temperatury, jak i objętości), co umożliwia przewidywanie wpływu tego paliwa na jego eksploatację w silnikach.

Początkowy zakres temperatury destylacji paliwa, do $70^{\circ} \mathrm{C}$ (E70), odpowiada za łatwość rozruchu zimnego silnika, nagrzewanie się silnika, emisję par i tworzenie się korków parowych. Środkowy zakres temperatur destylacji, tj. pomiędzy $70 \div 100^{\circ} \mathrm{C}$ (E100), wiąże się z szybkością rozgrzewania silnika, uzyskaniem odpowiedniego przyspieszenia i pracą silnika w warunkach zimowych [3]. Końcowy zakres temperatur destylacji, tj. powyżej $150^{\circ} \mathrm{C}(\mathrm{E} 150 \mathrm{i} \mathrm{TKD})$, odnosi się do skłonności paliwa do tworzenia osadów i rozcieńczania oleju smarującego $[18,16,30]$.

W celu lepszego wyjaśnienia zjawisk zachodzących w mieszaninach alkoholowo-benzynowych i ich wpływu na właściwości eksploatacyjne tych substancji zbadano mieszaniny etanolu, metanolu, $\mathrm{n}$ - $\mathrm{i}$ izopropanolu oraz czterech izomerów butanoli z benzyną w zakresie udziału alkoholi $5 \div 85 \%$ [1]. W odniesieniu do mieszanin z etanolem stwierdzono, że dodatek $5 \div 25 \%$ etanolu do benzyny silnikowej nie wpływa znacząco na temperaturę początku destylacji (IBP) [1]. Znaczny spadek temperatury dało się natomiast zaobserwować w środkowej części krzywej destylacji. Małe ilości etanolu (5 i 10\%) spowodowały największy wzrost lotności benzyny, szczególnie do około $30 \%$ objętości odparowania. W miarę wzrostu udziału etanolu krzywa destylacji przesuwała się stopniowo bliżej krzywej destylacji benzyny bazowej w obszarze powyżej $30 \%$ odparowania. Temperatury destylacji benzyny E5 wzrastają wolniej niż dla benzyny bazowej w obszarze T10 do T30, a następnie obserwuje się gwałtowny wzrost przy T50, gdzie osiągana jest taka temperatura jak w przypadku benzyny bazowej (E0). Kształt krzywych w tym obszarze świadczy o tworzeniu przez etanol mieszanin azeotropów z węglowodorami [1], a tym samym - o dużo większym wpływie tegoż etanolu na lotność paliwa niż ma to miejsce w mieszaninach idealnych [15, 24]. Podobne wyniki otrzymali inni badacze $[8,9]$ - dodatek etanolu w ilości $10 \%$ prowadził do znacznego spadku temperatury odparowania w zakresie pierwszych $40 \%$ objętości odparowania.

Analiza dostępnych danych europejskich, amerykańskich i australijskich, dotyczących badań nad wpływem etanolu na ilość paliwa odparowującego do $70^{\circ} \mathrm{C}$, prowadzi do twierdzenia, że przyrost $\Delta \mathrm{E} 70$ maleje wraz ze wzrostem E70 paliwa bazowego [26]. Dla mieszanin zawierających 10, 15, i $20 \%(V / V)$ etanolu zaobserwowano wartości $\Delta \mathrm{E} 70$ do $30 \%(V / V)$ przy niższych poziomach E70 paliwa bazowego. Przyrosty $\Delta$ E70 do $10 \%(V / V)$ etanolu są gwałtowne, a przyrosty dla wyższych poziomów $15 \div 20 \%(V / V)$ wykazują szeroki zakres wartości pomiędzy $10 \div 30 \%(V / V)[23]$. Twierdzenie to napotyka na konkluzję: proces mieszania objętościowego etanolu $\mathrm{z}$ benzyną nie jest prostym procesem liniowym [26]. Jest on wrażliwy na właściwości benzyny bazowej. Zaobserwowano, że rozpiętość wartości przyrostów $\Delta \mathrm{E} 100$ była znacznie mniejsza niż w przypadku $\Delta$ E70, zwłaszcza przy niższych stężeniach etanolu [26]. Wyższe poziomy zawartości etanolu generowaty przyrosty $\Delta \mathrm{E} 100$ do $20 \%(V / V)$. Przyrosty $\Delta \mathrm{E} 100$ malały również wraz ze wzrostem E100 paliwa bazowego.

Nieaddytywność parametru składu frakcyjnego benzyny, zawierającej etanol, jest przedmiotem badań prowadzonych 
w Instytucie Nafty i Gazu - Państwowym Instytucie Badawczym. W czasie mieszania ze sobą frakcji węglowodorowych, a także etanolu, występują dodatnie i ujemne efekty tego procesu. Dlatego też predykcja tych właściwości jest przedsięwzięciem trudnym. Przedstawiono obliczenia poszczególnych parametrów składu frakcyjnego benzyny finalnej z wykorzystaniem wyznaczonych $\mathrm{w}$ doświadczeniach addytywnych wskaźników poszczególnych komponentów benzyny [13]. Autorzy innego opracowania [4] podjęli próbę obliczenia destylacyjnych parametrów nieaddytywnych metodą addytywnych wskaźników mieszania. Wyniki badań i obliczeń pozwoliły na opracowanie modelu matematycznego umożliwiającego obliczanie wartości parametrów destylacji finalnej benzyny E10 na podstawie składu frakcyjnego komponentów benzynowych i etanolu.

W kolejnej publikacji [19] badano wpływ etanolu na parametry destylacji próbek benzyn różniących się zawartością frakcji C4 i koncentracją etanolu w zakresie $5 \div 10 \%(V / V)$. Największy wpływ odnotowano dla zawartości 10\% (V/V) etanolu, gdzie przyrost E70 wynosił kilkanaście procent, przy braku frakcji C4. Dla tej zawartości etanolu przyrost E100 pozostawał na poziomie kilku procent.

\section{Wpływ temperatur odparowania paliwa na właściwości eksploatacyjne silników o zapłonie iskrowym}

Specyfikacja amerykańska benzyny określa wartości temperatur odparowania 10, 50 i 90\% objętości paliwa. Limit wartości temperatury T50 podawany jest $\mathrm{w}$ przedziale minimum-maksimum, a dla T10 i T90 określony jest tylko limit górny. W przypadku mieszanin benzyny bazowej z różnymi alkoholami wartości te mogą zmieniać się w znacznym stopniu. Wyniki badań wskazują na to, że temperatura odparowania $50 \%$ paliwa (T50) została zmniejszona o $30^{\circ} \mathrm{C}$ (lub więcej) dla paliw zawierających $15 \%$ i więcej etanolu [1]. Autorzy publikacji uważają, że sugeruje to, iż stosowanie mieszanin etanolu z benzyną silnikową o stężeniach etanolu wyższych niż 10\% (np. E20) może wymagać zmiany kalibracji silnika, w celu uzyskania optymalnych warunków jego pracy, jeśli nie nastąpią zmiany w formule benzyny bazowej.

Z kolei wpływ etanolu na T10 dla niskiego (E5 i E10) i średniego jego udziału (E15-E25) w mieszaninie z benzyną jest niewielki, natomiast przy wyższych udziałach (E50, E85) - znaczny [1]. Wartość temperatury odparowania 10\% objętości paliwa (T10) jest szczególnie ważna dla pracy silnika i musi być ona wystarczająco niska, aby zapewnić prawidłowy rozruch silnika w niskich temperaturach otoczenia. Wpływ etanolu na T10 jest niewielki przy jego zawartościach do $25 \%$, ale znacząco zwiększa się przy wyższych ilościach, stwarzając określone problemy [1].

Badania wskazują na to, że wpływ wszystkich alkoholi, w tym etanolu, na temperaturę odparowania $90 \%$ paliwa wyrażał się obniżeniem jej wartości [1]. Autorzy publikacji zaznaczają, że ze względu na fakt ustalonego wysokiego limitu tej wartości (Europa - 210, USA - 225), wpływ na ten parametr składu frakcyjnego jest uważany za mało istotny. $\mathrm{Na}$ podstawie uzyskanych wyników stwierdzili oni, że dla mieszanek ze średnim $(15 \div 25)$ i wysokim $(50 \div 85 \%)$ udziałem alkoholi, w tym etanolu, powinny być podjęte środki umożliwiające bezproblemowe zastosowanie tych paliw w silnikach spalinowych. Środki te mogłyby obejmować między innymi:

- sezonowe zmiany udziału alkoholu w benzynie bazowej, jak ma to miejsce w przypadku komercyjnego paliwa etanolowego E85,

- zmiany w kalibracji silnika, jak odbywa się to w amerykańskich FFV i/lub zastosowanie dodatkowego zbiornika na paliwo o wyższej lotności dla rozruchu zimnego silnika, jak ma to miejsce obecnie w Brazylii w przypadku pojazdów zasilanych uwodnionym etanolem.

W omawianej publikacji [1] jest mowa także o potrzebie rewizji lub opracowania norm dla tego typu paliw, jak miało to miejsce w przypadku paliwa E85, dla którego stworzono normę ASTM D 5798. Autorzy zaznaczyli, że zastosowanie mieszaniny więcej niż jednego alkoholu z benzyną może być bardziej opłacalnym podejściem, gdyż ograniczy to skutki większej zawartości tylko jednego alkoholu i zapewni mniejszy wpływ na funkcjonowanie silnika samochodowego. Wyniki badań wskazują na to, że takim przykładem może być mieszanina zawierająca 10\% etanolu i 10\% 1-butanolu (w sumie 20\% alkoholu), która charakteryzowała się znacznie mniejszym wpływem na temperatury odparowania w zakresie T20 do T70 niż mieszanina zawierająca etanol w udziale od $10 \div 20 \%$.

\section{Wpływ etanolu na prężność par}

Prężność par określa łatwość uruchamiania silnika samochodowego i skłonność paliwa do tworzenia korków parowych. Parametr ten stanowi dodatkowy wskaźnik oceny lotności paliwa i jest powiązany $\mathrm{z}$ temperaturą początku destylacji oraz E70. Benzyny o dużej lotności odparowują bardzo szybko, co z jednej strony jest korzystne dla uruchamiania silnika w niskich temperaturach, $\mathrm{z}$ drugiej jednak strony może powodować powstawanie korków parowych i zaburzać proces spalania, prowadząc nawet do zatrzymania silnika [20]. Według C. Kajdasa [14] graniczna prężność par 
paliwa, przy której możliwe jest uruchomienie silnika w temperaturze poniżej $0^{\circ} \mathrm{C}$, wynosi $33,3 \mathrm{kPa}$. Ustalanie optymalnego składu frakcyjnego benzyny silnikowej polega więc na pogodzeniu łatwości odparowania z uniknięciem tworzenia niebezpiecznych korków parowych [20].

Jak wiadomo, etanol - charakteryzując się mniejszą masą cząsteczkową niż większość węglowodorów obecnych w benzynie - jest cieczą w temperaturze otoczenia, co wynika z silnych oddziaływań wiązań wodorowych pomiędzy cząsteczkami alkoholu. Ponieważ te oddziaływania wiązań wodorowych w benzynie węglowodorowej są albo bardzo słabe lub nie występują w ogóle, tłumaczy to fakt, że czysty etanol ma znacznie mniejszą prężność par niż benzyna $[10,26]$.

Jednak w przypadku zmieszania etanolu, szczególnie niewielkich jego ilości, z węglowodorami obserwowany jest wzrost lotności mieszanin etanol-benzyna. Przy zawartości etanolu $2 \%(V / V)$ wzrost ten wynosi $6 \div 8 \mathrm{kPa}$, co zostało już wielokrotnie udowodnione [26]. Autorzy publikacji [26] podkreślają, że im niższa prężność par benzyny bazowej, tym większy przyrost prężności par mieszaniny benzyny z etanolem. Zjawisko to, jako pozytywne odchylenie od zachowania się mieszaniny idealnej według prawa Raoult'a, jest wynikiem różnic w siłach oddziaływania pomiędzy cząsteczkami etanolu i węglowodorów a cząsteczkami w każdej cieczy z osobna. W przypadku mieszaniny benzyna-etanol siły te są słabsze, co ułatwia odparowywanie. Zależność prężności par od udziału etanolu w benzynie nie jest wystarczająco wyjaśniona, jak zauważają autorzy [26]. Wiadomo natomiast, że im więcej etanolu w mieszaninie $\mathrm{z}$ benzyną, tym mniejsze są przyrosty prężności par [22].

Prężność par benzyny związana z zawartością etanolu wpływa na emisję par z nowoczesnych samochodów [12]. Głównymi źródłami emisji par przez pojazd jest parowanie przez odpowietrzenie zbiornika paliwa, a także przenikanie paliwa przez elementy układu paliwowego wykonane z tworzyw sztucznych i gum [12]. Straty na skutek parowania paliwa przez odpowietrznik zbiornika paliwa powodowane są przez odparowanie benzyny w zbiorniku podczas jazdy w wysokiej temperaturze oraz normalne dobowe wahania temperatury otoczenia. We współczesnych pojazdach emisja par jest kontrolowana za pomocą urządzenia z węglem aktywowanym, które jest połączone z odpowietrzeniem zbiornika paliwa. Badania emisji par przeprowadza się na podstawie europejskiej homologacyjnej procedury testowej [12].

\section{Podsumowanie}

Niniejszy przegląd działań rządów w różnych regionach świata, w tym w Europie, w kierunku zwiększenia wykorzystania etanolu jako komponentu benzyny silnikowej, wskazuje, że także w Polsce należy podejmować odpowiednie działania, mając na uwadze rozwój przemysłowy. Przedstawione w tym artykule przykłady badań różnych ośrodków naukowych stanowią tylko niewielką część prac dotyczących paliw, które mają być przedmiotem obrotu. Ponieważ artykuł ten stanowi przegląd literatury, wykonany w ramach pracy statutowej dotyczącej badania zmian nieaddytywnych parametrów jakościowych benzyny silnikowej E15-E25 o zwiększonej zawartości bioetanolu, dotyczy on tylko aspektu lotności. W kolejnym artykule Aspekty wprowadzania średniego poziomu zawartości etanolu do benzyny silnikowej - Część 2 przedstawione zostaną wyniki badań INiG - PIB, uzyskane w pracy badawczej.

Prosimy cytować jako: Nafta-Gaz 2016, nr 2, s. 112-117, DOI: 10.18668/NG.2016.02.06

Artykuł nadesłano do Redakcji 16.11.2015 r. Zatwierdzono do druku 18.01.2016 r.

Artykuł powstał na podstawie pracy statutowej pt. Badanie zmian nieaddytywnych parametrów jakościowych benzyny silnikowej E15-E25 o zwiększonej zawartości bioetanolu - praca INiG - PIB na zlecenie MNiSW; nr zlecenia: 0014/TP/15/01, nr archiwalny: DK-4101-14/15.

\section{Literatura}

[1] Andersen V. F., Anderson J. E., Wallington T. J., Mueller S. A., Nielsen O. J.: Distillation Curves for Alcohol-Gasoline Blends. Energy Fuels 2010, vol. 24, nr 4, s. 2683-2691; doi: $10.1021 / \mathrm{ef} 9014795$

[2] BioEthanol for Sustainable Transport Results and recommendations from the European BEST Project; www.best-europe. org (dostęp: maj 2015)

[3] Bruno T. J., Wolk A., Naydich A.: Composition-Explicit Distillation Curves for Mixtures of Gasoline with Four-Carbon Alcohols (Butanols). Energy Fuels 2009, vol. 23 nr 4, s. 2295 2306; doi: 10.1021/ef801117c.
[4] Danek. B., Rogowska D.: Destylacja benzyny silnikowej z zawartościa do $10 \%(\mathrm{~V} / \mathrm{V})$ etanolu - obliczanie jej parametrów metodą addytywnych wskaźników mieszania. Nafta-Gaz 2014, nr 3, s. 192-196.

[5] de Menezes E. W., Cataluña R., Samios D., da Silva R.: Addition of an azeotropic ETBE/ethanol mixture in eurosupertype gasolines. Fuel 2006, vol. 85, nr 17-18, s. 2567-2577; doi: 10.1016/j.fuel.2006.04.014.

[6] Environmental Protection Agency [EPA-HQ-OAR-20090211; FRL-9258-6] Partial Grant of Clean Air Act Waiver Application Submitted by Growth Energy To Increase the 
Allowable Ethanol Content of Gasoline to 15 Percent. Decision of the Administrator. Federal Register, vol. 76, nr 17, Wednesday, January 26, 2011, Notices.

[7] Federal Register, vol. 76, nr 17, Wednesday, January 26, 2011, Notices, s. 4662.

[8] Furey R.: Volatility Characteristics of Gasoline-Alcohol and Gasoline-Ether Fuel Blends. SAE Technical Paper 852116, 1985, doi: 10.4271/852116.

[9] Greenfield M. L., Lavoie G. A., Smith C. S., Curtis E. W.: Macroscopic Model of the D86 Fuel Volatility Procedure. SAE Technical Paper 982724, 1998; doi: 10.4271/982724.

[10] Guidelines for blending and handling motor gasoline containing up to $10 \%$ v/v ethanol. Report 3/2008, CONCAWE, Brussels, April 2008.

[11] Horizon 2020 Work Programme 2014-2015 10. Secure, clean and efficient energy. European Commission Decision C (2015) 2453 of 17 April 2015; http://ec.europa.eu/ research/participants/data/ref/h2020/wp/2014_2015/main/ h2020-wp1415-energy_en.pdf (dostęp: kwiecień 2015).

[12] Joint EUCAR/JRC/CONCAWE Study on: Effects of Gasoline Vapour Pressure and Ethanol Content on Evaporative Emissions from Modern Cars. Institute for Environment and Sustainability 2007, EUR 22713 EN.

[13] Kaczmarczyk A., Rogowska D.: Zmodyfikowana metoda McLeana-Andersona planowania doświadczeń dla opracowywania modeli matematycznych właściwości mieszanin. Biuletyn Instytutu Technologii Nafty 2002, nr 2, s. 94-100.

[14] Kajdas C.: Podstawy zasilania paliwem i smarowania samochodów. WKiŁ. Warszawa 1983, s. 292-293.

[15] Kar K., Last T., Haywood C., Raine R.: Measurement of Vapor Pressures and Enthalpies of Vaporization of Gasoline and Ethanol Blends and Their Effects on Mixture Preparation in an SI Engine. SAE International Journal of Fuels and Lubricants 2009, 1 (1), s. 132-144; doi: 10.4271/2008-01-0317.

[16] Motor Gasolines Technical Review (FTR-1), 2009; www. chevron.com/products/ourfuels/prodserv/fuels/technical safety bulletins/ (dostęp: wrzesień 2015).

[17] Muzikova Z., Pospisil M., Sebor G.: Volatility and phase stability of petrol blends with ethanol. Fuel 2009, vol. 88, nr 8, s. 1351-1356; doi: 10.1016/j.fuel.2009.02.003.

[18] Owen K., Coley T.: Automotive Fuels Reference Book. Second Edition. Society of Automotive Engineers Inc., Warrendale 1995.

[19] Pałuchowska M., Rogowska D.: Wplyw bioetanolu na nieaddytywne właściwości benzyny silnikowej. Nafta-Gaz 2009, nr 1, s. 21-28.

[20] Podniało A.: Paliwa, oleje i smary w ekologicznej eksploatacji. WNT. Warszawa 2002, s. 28-29.

[21] Preliminary Examination of Ethanol Fuel Effects on EPA's R-factor for Vehicle Fuel Economy. ORNL/TM-2012/198, June 2013

[22] Robert L., McCormick R. L., Yanowitz J.: Discussion Document - Effect of Ethanol Blending on Gasoline RVP; http://www.ethanolrfa.org/page/-/RVP\%20Effects\%20 Memo 03 26 12 Final.pdf?nocdn=1.

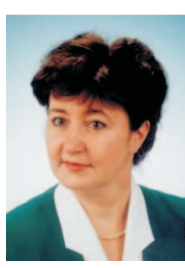

Dr inż. Martynika PAŁUCHOWSKA

Główny specjalista badawczo-techniczny

w Zakładzie Paliw i Procesów Katalitycznych.

Instytut Nafty i Gazu - Państwowy Instytut Badawczy

ul. Lubicz 25 A

31-503 Kraków

E-mail: martynika.paluchowska@inig.pl
[23] Smith B. L., Bruno T. J.: Improvements in the Measurement of Distillation Curves. 3. Application to Gasoline and Gasoline + Methanol Mixtures. Industrial \& Engineering Chemistry Research 2007, vol. 46, nr 1, s. 297-309; doi: 10.1021/ie060937u.

[24] Takeshita E. V., Rezende R. V. P., Gueli U. de Souza S. M. A., Ulson de Souza A. A.: Influence of solvent addition on the physicochemical properties of Brazilian gasoline. Fuel 2008, vol. 87 , nr 10-11, s. 2168-2177; doi: 10.1016/j.fuel.2007.11.003.

[25] The rational utilization of fuels in private transport (RUFIT) extrapolation to unleaded gasoline case, report 8/80; CONCAWE 1983, Oil Companies International Study Group for Conservation of Clean Air and Water. Europe, Den Haag, Netherlands; http://download-v2.springer.com/static/pdf/198/ chp\%253A10.1007\%252F978-94-009-7197-4 26.pdf?token2 $=$ exp $=1429530077 \sim$ acl $=\% 2$ Fstatic $\% 2 F p d f \% 2 F 198 \% 2 F c h-$ p\%25253A10.1007\%25252F978-94-009-7197-4_26.pdf* h$\mathrm{mac}=49 \mathrm{~d} 549 \mathrm{e} 7689296543 \mathrm{cc} 17 \mathrm{a} 0 \mathrm{~b} 013 \mathrm{fe} 79896 \mathrm{c} 78 \mathrm{f} 176 \mathrm{e}-$ 0a0e720e3717b0ee01d019 (dostęp: kwiecień 2015).

[26] TREN/D2/454-2008-SI.2.522.698 (Final Report) 12.31.2009. Ethanol/Petrol Blends: Volatility Characterisation in the Range 5-25 vol\% (BEP525); https://ec.europa.eu/energy/sites/ ener/files/documents/2010 bep525 final report.pdf.

[27] West B.: Etanol as a Spark Ignition Engine Fuel. Fuels, Engines, and Emissions Research Center Oak Ridge National Laboratory, National Ethanol Conference, February 18-19, 2014 (dostęp: kwiecień 2015).

[28] Woebkenberg W.: Mid-Blend Ethanol Fuels - Implementation Perspectives. US Fuels Technical and Regulatory Affairs, Mercedes-Benz Research \& Development North America, July 25, 2013 (htpp: prezentacja Mercedes-Benz).

[29] Yanowitz J., Ratcliff M., Zigler B. T., McCormick R. L.: IncStudies on the Use of E15 and E20 in Light-Duty Vehicles. National Renewable Energy Laboratory, Ecoengineering.

[30] Zwierzycki W.: Oleje, paliw i smary dla motoryzacji i przemystu. Wydawnictwo i Zakład Poligrafii Instytutu Technologii Eksploatacji. Radom 2001.

\section{Akty prawne i normatywne}

[31] Dyrektywa Parlamentu Europejskiego i Rady 2009/28/WE $z$ dnia 23 kwietnia 2009 r. w sprawie promowania stosowania energii ze źródet odnawialnych.

[32] Dyrektywa Parlamentu Europejskiego i Rady 2009/30/WE z dnia 23 kwietnia 2009 r. zmieniajaca dyrektywę 98/70/WE odnoszaca się do specyfikacji benzyny i olejów napędowych oraz wprowadzajaca mechanizm.

[33] Służba Celna Rzeczypospolitej Polskiej System ISZTAR - Informacja Taryfowa; http://145.237.239.200/ isztar/taryfa_celna/web/browsetariffi2_PL? expandele$\mathrm{m}=27101249 \&$ Year $=2017 \&$ Month $=02 \&$ Day $=12 \&$ Country $=-\&$ issection $=$ \& $\&$ checkfinal $=y \&$ impexp $=\# P O S$ (dostęp kwiecień 2015).

[34] Ustawa z dnia 15 stycznia 2015 r. o zmianie ustawy o biokomponentach i biopaliwach cieklych oraz niektórych innych ustaw (Dz. U. z 2014 roku nr 0, poz. 151).

Mgr inż. Bogusław HADUCH

Starszy specjalista badawczo-techniczny, kierownik Biura Kontroli. Instytut Nafty i Gazu - Państwowy Instytut Badawczy

ul. Lubicz 25 A

31-503 Kraków

E-mail: boguslaw.haduch@inig.pl 